\title{
Nanoporous nanocrystalline monoclinic zirconia for luminescent oxygen sensors
}

Janusz D. Fidelus

Wuzong Zhou

Tadeusz Tenderenda

Tomasz Nasiłowski 


\title{
Nanoporous nanocrystalline monoclinic zirconia for luminescent oxygen sensors
}

\author{
Janusz D. Fidelus $^{*}$,b, Wuzong Zhou ${ }^{\mathrm{c}}$, Tadeusz Tenderenda ${ }^{\mathrm{a}}$, Tomasz Nasilowski ${ }^{\mathrm{a}}$ \\ ${ }^{a}$ InPhoTech Ltd., Slominskiego 17/31, 00-195 Warsaw, Poland \\ ${ }^{b}$ Polish Academy of Sciences, Institute of High Pressure Physics, \\ Sokołowska 29/37, 01-142 Warsaw, Poland \\ ${ }^{\mathrm{c}}$ School of Chemistry, University of St Andrews, \\ KY16 9ST St Andrews, United Kingdom
}

\begin{abstract}
In this work we present a nanocrystalline monoclinic $\mathrm{ZrO}_{2}$ with large free volumen open towards the nanocrystals surface dedicated for optical oxygen sensors. Nanoporous zirconia nanopowder was fabricated in hydrothermal microwave-driven process followed by annealing at $800^{\circ} \mathrm{C}$. Metal-coated optical fibers are proposed as a light carrier when the working temperature exceeds $500^{\circ} \mathrm{C}$. The obtained results may also find application in luminescent fiber optic oxygen sensors.
\end{abstract}

Keywords: optical oxygen sensor, microstructured optical fibers (MOF), fiber optic sensor, temperature sensor

\section{INTRODUCTION}

A technology foresight study on sensor technology conducted in 2004 [1] reported that the MEMS (Micro-ElectroMechanical Systems), optical and biochemical sensors will be the most interesting sensor categories over the next 10 years regarding market volume. At the same time, tremendous attention was focused on fiber optic sensors, FOS, (including Microstructured Optical Fibers, MOF), due to their remarkable properties. These materials have revolutionized a multitude of various sensing applications [2, 3], including sensing in harsh environments [4]. Therefore, they are appreciated by the industry, since it is predicted that the FOS market will surpass 2.5 billion USD in 2017 [5]. On the other hand, the discovered luminescence sensitivity for oxygen content in zirconia nanostructures [6-9] have recently become of important scientific and technological interest. This finding allows for the development of solid state luminescent oxygen sensors which could be potentially used in many industries, transport and facilities for public use (for environmental monitoring, technological process control etc).

It is known that the exchange of oxygen between nanocrystals and surrounding gasses is defect related and strongly depends on the nanocrystals' properties. Therefore it is important to manufacture stable nanoporous $\mathrm{ZrO}_{2}$ material with good luminescent properties. The pure $\mathrm{ZrO}_{2}$, wide band gap semiconductor exists in three polymorphic phases at ambient pressure: monoclinic (M) [10], tetragonal (T) [11], and cubic (C) [12] at high temperatures (above $2370^{\circ} \mathrm{C}$ where the $\mathrm{T}-\mathrm{C}$ transition occur). The $\mathrm{M}-\mathrm{T}$ transformation is observed at $1170^{\circ} \mathrm{C}$. Below this temperature the material transforms to the M phase, which is thermodynamically stable [13].

In this work selected results on fabrication and characterization of microporous monoclinic nanopowders for luminescence oxygen sensor application are presented. In addition, some technical solutions (the use of appropriate metal coated fibers) for sensor system working in temperatures above $500^{\circ} \mathrm{C}$ are proposed.

*jfidelus@inphotech.pl, www.inphotech.pl

24th International Conference on Optical Fibre Sensors, edited by Hypolito José Kalinowski, José Luís Fabris, Woitek J. Bock, Proc. of SPIE Vol. 9634, 96345A · @ 2015 SPIE CCC code: $0277-786 X / 15 / \$ 18 \cdot$ doi: $10.1117 / 12.2195244$ 


\section{SAMPLE PREPARATION}

Nanoporous nanocrystalline monoclinic zirconia was successfully synthesized through hydrothermal microwave driven process (MW), described in details in [9], and then heated in air up to $800^{\circ} \mathrm{C}$ at a rate of $15{ }^{\circ} \mathrm{C} \mathrm{min}{ }^{-1}$, held at this temperature for $30 \mathrm{~min}$ and subsequently cooled down. The syntheses were performed in MW\&HP ERTEC reactor under a pressure of $6 \mathrm{MPa}$ (accuracy-0,5 MPa) at $280^{\circ} \mathrm{C}$ (calculated from $\mathrm{p} / \mathrm{T}$ diagram for water) for $30 \mathrm{~min}(20 \mathrm{~min}$ heating, 10 min cooling). This thermal treatment permits to obtain particles of the monoclinic phase (Figure 1, Figure 2) and grain size stable up to $\sim 700{ }^{\circ} \mathrm{C}$, i.e., at the temperature at which the samples in sensor material may be annealed under variable oxygen pressure.

\section{SAMPLE CHARACTERIZATION}

The $\mathrm{ZrO}_{2}$ powder was characterized by x-ray diffraction (XRD) using a Philips X'pert MPD ALPHA1 PRO diffractometer operating at $40 \mathrm{kV}$ and $30 \mathrm{~mA}$ with $\mathrm{Cu} \mathrm{K} \alpha 1$ radiation, equipped with a primary-beam Johansson $\mathrm{Ge}$ monochromator and a strip detector. Data were collected in a continuous mode, and recorded with a step length of 0.0167 in the angular region of $2 \theta$ from $5^{\circ}$ to $159^{\circ}$. The $\mathrm{XRD}$ pattern show that $\mathrm{ZrO}_{2}$ is composed of monoclinic phase only after annealing at $800^{\circ} \mathrm{C}$. The phase content, lattice parameters and the average crystallites size determined by XRD using the Scherrer equation are shown in Table 1.

Table 1. Phases content (weight \%), lattice parameters and the grain size in $\mathrm{ZrO}_{2}$ sample annealed at $800^{\circ} \mathrm{C}$.

\begin{tabular}{|c|c|}
\hline Sample & $\mathbf{Z r O}_{\mathbf{2}}-\mathbf{8 0 0}^{\circ} \mathbf{C}$ \\
\hline $\mathrm{a}[\AA]$ & $5.1481(3)$ \\
\hline $\mathrm{b}[\AA]$ & $5.2051(3)$ \\
\hline $\mathrm{c}[\AA]$ & $5.3196(3)$ \\
\hline $\mathrm{b}$ & $99.187(5)$ \\
\hline & Phases content (weight \%) \\
\hline $\mathrm{M}[\%]$ & $100 \%$ \\
\hline & Grain size [nm] \\
\hline $\mathrm{M}[\mathrm{nm}]$ & $26.3(1)$ \\
\hline
\end{tabular}

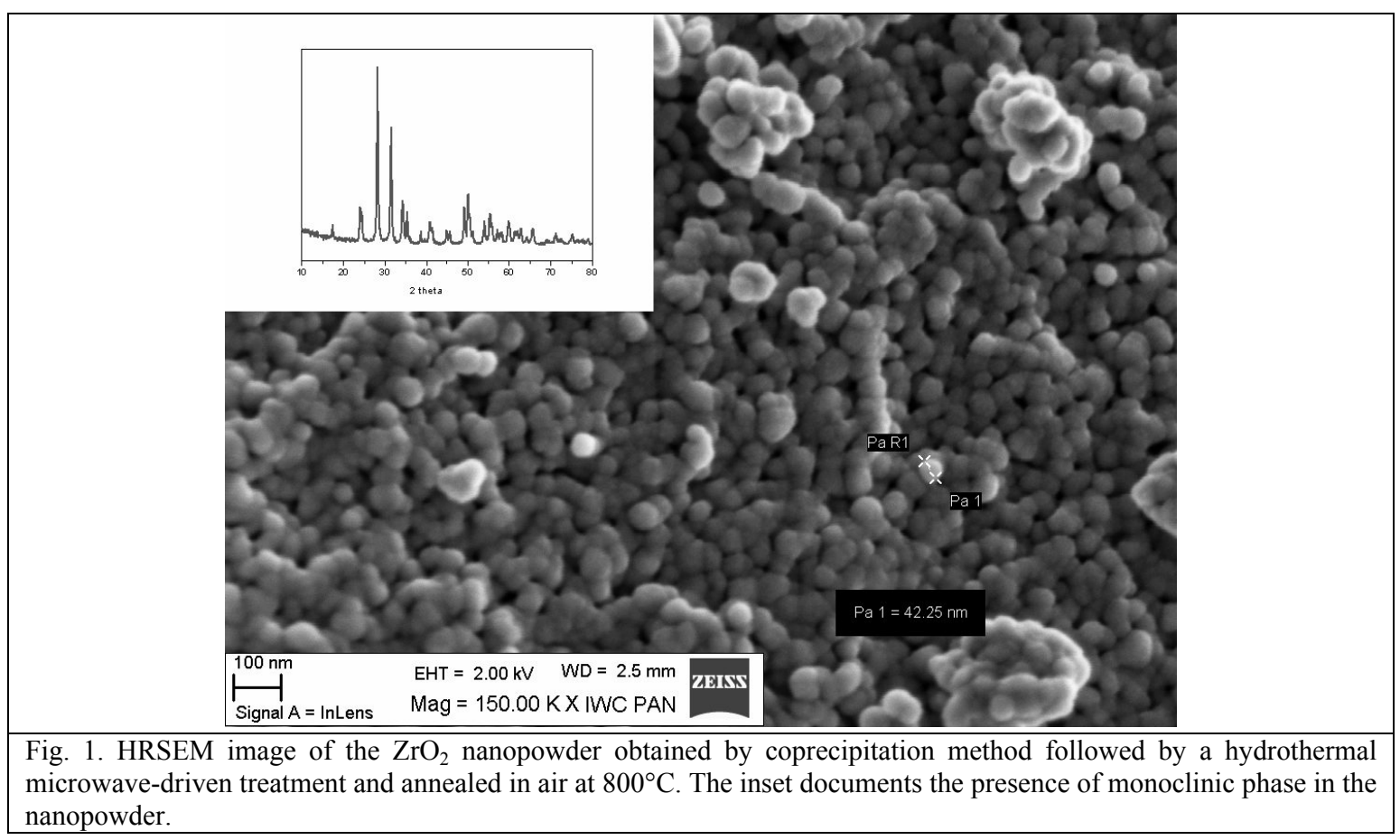




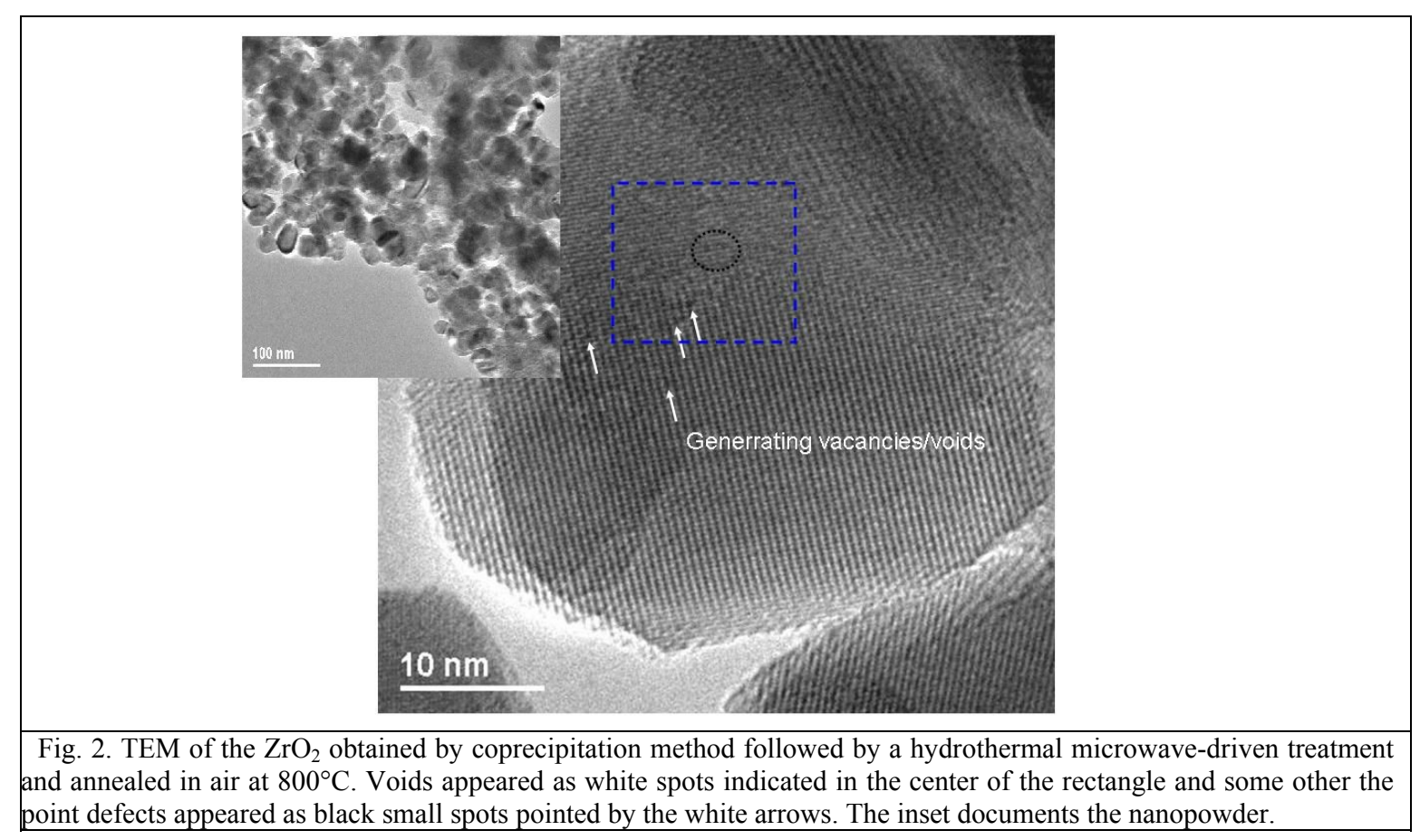

The sample morphology was determined using a LEO 1530 field emission scanning microscope and TEM, JEOL JEM-2010HR electron microscope operated at $200 \mathrm{kV}$ and equipped with a Gatan GIF Tridiem system. Fig. 1 shows the morphology of $\mathrm{ZrO}_{2}$. The structure is uniform with fine, spherical particles agglomerated into larger aggregates of approximately $40 \mathrm{~nm}$ diameter. The average size of the annealed $\mathrm{ZrO}_{2}$ nanocrystals, based on XRD analysis, was 26,3(1) $\mathrm{nm}$. This value is in reasonable agreement with the TEM observation presented in Figure 2. The microscopic study revealed voids with $\approx 2-3 \mathrm{~nm}$ in diameter appear as white spots indicated in the center of the rectangle. Other, point defects appeared as black small spots pointed by the white arrows. The good luminescence properties of nanopowders annealed at $800^{\circ} \mathrm{C}$ as well as large (at least few atomic units) free volumen open towards the $\mathrm{ZrO}_{2}$ nanocrystals surface was confirmed by positron annihilation spectroscopy study in previous works $[9,14]$.

The specific surface area analysis was determined by the multipoint B.E.T. method (Gemini 2360, Micromeritics Instruments). The results of specific surface analysis $\sim 30 \mathrm{~m}^{2} / \mathrm{g}$, are consistent with this grain-size range. The density of the annealed nanopowder was measured by means of helium picnometry using a AccuPyc 1330, produced by Micrometrics Instruments. High density, $\sim 5,9 \mathrm{~g} / \mathrm{cm}^{3}$, of nanopowder indicate its good quality with a high degree of crystallinity what is illustrated in Figure 2.

\section{HIGH TEMPERATURE LUMINESCENCE OXYGEN SENSOR}

Here we propose improvement/technical solution for optical sensor operating at high temperatures having metal-coated optic fibers as a light supplier. Our previous work $[15,16]$ showed that developed optical fiber with nickel protective layer ( $\mathrm{Ni}$ is a diffusion barrier and additional protection) are resistant to the oxidation process, the method of protecting the fiber is robust and may find application in industrial fiber sensors. Scheme of an optical oxygen sensor located in the exhaust of a temperature ranging from $350^{\circ} \mathrm{C}$ to $700^{\circ} \mathrm{C}$ is shown on Fig. 3. The principle of operation of the oxygen sensor is as follows: a layer of nanocrystalline zirconia powder (2) (in contact with the gaseous atmosphere) is illuminated by the UV light source (3). The light is supplied by the metal-coated fiber (MCF). Luminescent light is detected by the photodetector (4), and then records the intensity and luminescence decay time (5). The powder emits light whose intensity depends on the partial pressure of oxygen in contact with it. In parallel (at the same measurement) to the luminescence decay time, the temperature of the heated nanoporous nanopowder is also determined. Details of zirconium dioxide oxygen sensor luminescence can be found in a recent patent [6]. Mechanism of luminescence intensity dependence on oxygen pressure and the model of the luminescence centre in $\mathrm{ZrO}_{2}$ nanoparticles were described in details in $[8,9]$. In order to fully exploit the optical fiber it is suggested to cover it by nanoporous zirconia with the sputtering method in order to obtain luminescent fiber optic oxygen sensors. 


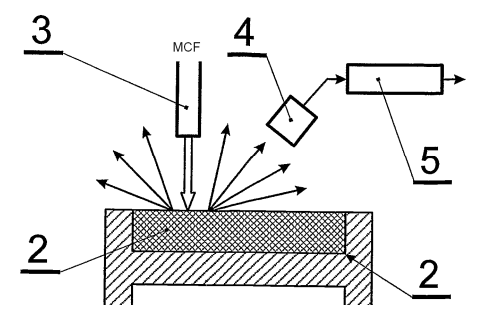

Fig. 3. Scheme of optical oxygen sensor: (2) a layer of nanocrystalline zirconia powder; (3) UV light source supplied by MCF; (4) photodetector; (5) recorder of intensity and luminescence decay time.

\section{CONCLUSIONS}

We have presented a nanocrystalline monoclinic $\mathrm{ZrO}_{2}$ with good luminescent properties and large free volumen open towards the nanocrystals surface dedicated for optical oxygen sensors. Nanoporous zirconia nanopowder was obtained in hydrothermal microwave-driven process followed by annealing up to $800^{\circ} \mathrm{C}$. Metal-coated optical fibers are proposed as an light source when the working temperature exceeding $500^{\circ} \mathrm{C}$. Moreover, it is predicted that the proposed solution may find application as an luminescent fiber optic oxygen sensor.

\section{ACKNOWLEDGMENTS}

The work described in this paper was partially supported by the grant no. N N508 085133 of Ministry of Science and Higher Education (Poland) and by the Innovative Economy Programme as project POIG.01.04.00-06-117/12.

\section{REFERENCES}

[1] Andersen, P.D. et al.,"Sensor foresight- - technology and market," Technovation, 24(4), 311-320 (2004).

[2] Frazão, O., et al. "Optical sensing with photonic crystal fibers," Laser \& Photonics Reviews, 2(6), 449-459 (2008).

[3] Murawski, M., Szymanski, M., Tenderenda, Mar, P., et al., "Strain and temperature sensitivity measurement using simple microstructured fiber Mach-Zhender interferometer," in Proc. SPIE - Int. Soc. Opt. Eng., 8421 (2012).

[4] Culshaw, B., et al. "Fiber-Optic Sensing: A Historical Perspective," J. Light. Technol., 26(9), (2008).

[5] "Fiber Optic Sensors: Global Markets," BCC Research, IAS002E, (2011).

[6] Łojkowski W, Millers D, Fidelus J. et al. "Zirconium dioxide luminescence oxygen sensor," EP 1920238 B1,

US 7, 888, 658 B2, EP 1920238 B1 (2005) assigned: Instytut Wysokich Cisnien Polskiej Akademii Nauk (Warsaw, PL).

[7] Fidelus, J.D., Łojkowski, W. Millers, D., Grigorjeva, L., Smits, K. , Piticescu, R. R. "Zirconia-based nanomaterials for oxygen sensor - generation, characterisation and optical properties,", Solid State Phenomena 128, 141-150 (2007).

[8] Fidelus, J.D., Łojkowski, W. Millers, D., Smits, K., Grigorjeva, L., "Advanced nanocrystalline $\mathrm{ZrO}_{2}$ for optical oxygen sensors", Proceedings of the International Conference of Sensors IEEE, 1268-1272 (2009).

[9] Fidelus, J.D., Karbowski, A., Werner-Malento, E., Brusa, R.S., Zhou, W., Karwasz G. P. et al., "Combined positron annihilation and structural studies of hydrothermally grown zirconia," Nanomaterials and Energy 1, 97-105 (2012).

[10] Smith, D.K. and Newkirk, H.W., "The crystal structure of baddeleyite (monoclinic $\mathrm{ZrO}_{2}$ ) and its relation to the polymorphism of $\mathrm{ZrO}_{2}$, “ Acta Crystallographica 18, 983-991 (1965).

[11] Teufer, G., "Crystal structure of tetragonal $\mathrm{ZrO}_{2}$," Acta Crystallographica 15, 1187-1188 (1962).

[12] Wyckoff, R.W.G. (ed.) [Crystal Structures]. 2nd edn. 1. Wiley, New York (1963).

[13] Subbarao, E.G., "Zirconia-an overview. In Advances in Ceramics/Science and Technology of Zirconia,” (Heuer AH and Hobbs, L.W. (eds)). Elsevier, Amsterdam, pp 1-24 (1981).

[14] Fidelus, J.D., Karbowski, A., Mariazzi, S., Brusa RS, Karwasz, G., "Positron-annihilation and photoluminescence studies of nanostructured $\mathrm{ZrO}_{2}$, “ Nukleonika 55, 85-89 (2010).

[15] Wysokiński, K., Stańczyk, T., Tenderenda, T., Nasilowski, T., "New methods of enhancing the thermal durability of silica optical fibers," Materials 7(10), 6947-6964 (2014).

[16] Stańczyk, T., Wysokiński, K., Tenderenda, T., Nasiłowski, T., „Electrolytic joints between metal surfaces and metal-coated fibers for application in high temperature optical fiber sensors,” Proc. SPIE, 9157 (2013). 